\title{
Prática de pesquisa e ensino de relações internacionais: relatos sobre experiência de pesquisa em comércio internacional
}

\section{Research practice and teaching of international relations: reports on research experience in international trade}

\author{
Patrícia Nasser de Carvalho - UFMG \\ Fernanda Cristina Nanci Izidro Gonçalves - IESP/UERJ e Unilasalle-RJ \\ Rafael Pinheiro de Araujo - IFS
}

\begin{abstract}
RESUMO: O presente artigo retrata a experiência da Unidade de Inteligência Comercial do curso de Relações Internacionais do Unilasalle-RJ entre 2014 e 2017. O objetivo é apresentar como a prática de pesquisa pode auxiliar a preparação dos discentes a partir de sua participação em atividades vinculadas à área de inteligência comercial. Dessa forma, apresenta-se a experiência discente e do grupo de pesquisa na elaboração de estudos para apoiar a formulação de políticas públicas para a área de comércio internacional, materializando a cooperação entre o Unilasalle-RJ e a Subsecretaria de Relações Internacionais do Governo do Estado do Rio de Janeiro.
\end{abstract}

Palavras-Chave: Comércio Internacional, Políticas Públicas, Prática de Pesquisa, Ensino.

\section{INTRODUÇÃO}

As pesquisas sobre o Ensino em Relações Internacionais no Brasil nos últimos anos ressaltam a institucionalização da disciplina, a expansão de cursos de graduação e pósgraduação, o incremento da produção intelectual e os desafios para a inserção dos profissionais da área no mercado de trabaIho (HERZ, 2002; LESSA, 2005).

A relevância de discutir o ensino na área propiciou a criação de um subcampo temático sobre Ensino e Pesquisa na Associação Brasileira de Relações Internacionais (ABRI), que congrega acadêmicos e pesquisadores em prol do estímulo à produção científica no Brasil no âmbito das Relações Internacionais. Além de incentivar a produção científica sobre ensino, a criação deste subcam- po fomentou o estímulo à troca de experiências de ensino-aprendizagem, atendendo, assim, a uma necessidade acadêmica decorrente da exígua produção de pesquisas nesse campo, se compararmos a outras, cujas temáticas estão mais consolidadas, como Segurança Internacional e Economia Política Internacional.

Com o intuito de contribuir com os debates acerca do ensino de Relações Internacionais, apresentamos um estudo de caso em nível de graduação que congrega atividades relacionadas ao conteúdo acadêmico da disciplina Comércio Internacional com o desenvolvimento de uma pesquisa de caráter técnico, cujo fim é apoiar a formulação de políticas públicas na área de inteligência comercial do governo do Estado do Rio de Janeiro. 
Assim, este artigo aborda a pesquisa na área de inteligência comercial desenvolvida pelo curso de Relações Internacionais do Unilasalle-RJ em parceria com a Subsecretaria de Relações Internacionais do Governo do Estado do Rio de Janeiro (SSRI) e com o financiamento da Fundação de Amparo à Pesquisa do Estado do Rio de Janeiro (FAPERJ). Esse projeto cooperativo originou a Unidade de Inteligência Comercial no Unilasalle-RJ, formada por docentes e discentes do bacharelado de Relações Internacionais.

A pesquisa desenvolvida na Unidade de Inteligência Comercial aborda a elaboração de estudos técnicos, como análises do desempenho comercial de bens e de setoreschave da economia do Estado do Rio de Janeiro ao longo da última década, a fim de apoiar o planejamento e a execução de políticas comerciais e industriais em nível subnacional, além da prospecção de novos mercados, de modo a alavancar as exportações fluminenses.

Diante da excelente oportunidade de unir o ensino teórico de sala de aula às atividades práticas em um modelo mais dinâmico de ensino, no qual os alunos desenvolveriam pesquisas e elaborariam estudos para auxiliar a tomada de decisão dos gestores públicos do Estado do Rio de Janeiro, os professores da instituição apostaram no projeto, lançado no final de 2014 pela SSRI. De imediato, entenderam que a pesquisa técnica complementaria a formação acadêmica do alunado, auxiliando a preparação dos estudantes para o mercado de trabalho, a partir do treinamento de análise e da elaboração de pesquisas em inteligência comercial, área em expansão e com inúmeras oportunidades nos setores público e privado.

Assim, debate-se neste artigo o Ensino das Relações Internacionais no Brasil, os desafios do processo de ensino-aprendizagem da área, com ênfase no campo de Comércio Internacional e os resultados desse projeto na área de Comércio Internacional.

\section{O ENSINO DAS RELAÇÕES INTERNACIO- NAIS NO BRASIL: UM BREVE RELATO HIS- TÓRICO}

A área de Relações Internacionais é relativamente nova no Brasil. O primeiro curso de graduação na área surgiu em 1974 na Universidade de Brasília (UNB), sendo seguido pela criação de cursos de pósgraduação. Até então, os estudos da área estavam associados a outros estudos correlatos, como História, Economia, Ciência Política (VIGEVANI, THOMÁZ, LEITE, 2014). A proliferação dos cursos de graduação se deu durante os anos 1990 e 2000 no bojo das transformações que marcaram as relações internacionais no pós-Guerra Fria e da crescente internacionalização da economia brasileira (MIYAMOTO, 2003; LESSA, 2005).

Nesse contexto, o interesse por compreender a inserção internacional do país e a oportunidade de um mercado de trabalho em organizações internacionais, organizações não-governamentais, na carreira diplomática, em assessorias internacionais no setor público e privado, na área de comércio exterior, no setor acadêmico e em áreas que trabalham com análises de riscos e investimentos propiciou a criação de diversos cursos de graduação em Relações Internacionais. Esses cursos, que possuem bases multidisciplinares e com ênfases diversas (como comércio exterior e estudos diplomáticos), buscam preparar um profissional com formação competitiva no mercado de trabalho, que possa atuar em múltiplas á- 
reas.

Todavia, como aponta Miyamoto (2003), a própria multidisciplinaridade dos cursos gera questionamentos sobre a inserção no mercado de trabalho, visto que não existe uma profissão específica para o chamado "internacionalista", mas diversas oportunidades de emprego na área (ALMEIDA, 2006). Assim, o desenvolvimento de atividades mais práticas, que sejam realizadas em paralelo à sala de aula, têm o potencial de auxiliar a preparação dos alunos para o mercado, desenvolvendo capacidade analítica e competências que são requeridas para um profissional competitivo.

Contudo, os desafios para formar estudantes capazes de se integrar de forma competitiva no mercado de trabalho envolvem diversas questões de natureza institucional e acadêmica. No âmbito institucional, nem todos os centros de ensino possuem estrutura adequada (como bibliotecas atualizadas, laboratórios equipados) e corpo docente especializado e com experiência profissional na área (MIYAMOTO, 2003). Na seara acadêmica, o modelo de ensinoaprendizagem, ainda muito atrelado ao padrão de ensino adotado no Ensino Fundamental e Médio, com alunos pouco participativos e padrões de avaliação como provas e trabalhos acadêmicos, constitui um verdadeiro desafio à formação adequada de quadros que participarão de empresas e instituições que têm que lidar de forma crítica e ágil às mudanças que ocorrem nas relações internacionais. Desse modo, trabaIhar o senso crítico, a capacidade analítica e propositiva dos discentes, a criatividade e o trabalho em equipe são desafios que se impõem aos docentes que integram os cursos da área.

No campo das Relações Internacionais um desafio adicional se impõe: lida-se com o internacional, o que aparentemente está muito distante do cotidiano e da realidade dos estudantes. É comum que os discentes questionem aos seus professores sobre a aplicabilidade dos conteúdos discutidos em sala de aula. Nesse sentido, é necessário que haja um esforço para aproximar o conteúdo apresentado aos estudantes - sobretudo no que tange às teorias, das Relações Internacionais ou de Comércio Internacional - aos acontecimentos reais da política internacional, aos efeitos da política exterior desenvolvida por um país e aos impactos da política comercial no comércio exterior de cada nação. Esse esforço pode se dar de diferentes maneiras, seja tanto através da discussão e análise de filmes, documentários e notícias de jornais, de atividades em laboratórios de pesquisa, da realização de visitas técnicas em instituições diversas como Embaixadas, Consulados, organizações internacionais e empresas multinacionais, quanto da realização de simulações e jogos, iniciativas que algumas instituições e docentes já têm feito. Assim, cabe aos professores e às instituições aplicarem novos métodos de ensino que desenvolvam habilidades e ofereçam aprendizado sobre ferramentas de trabalho úteis aos alunos a fim de que possam assimilar o conteúdo e aprimorarem suas habilidades de análise sem simplesmente memorizarem fatos e dados. Por meio de formas mais criativas e experiências práticas de ensino, eles aprenderão em que circunstâncias e áreas podem aplicar seus conhecimentos.

No Unilasalle-RJ, uma das formas encontradas para superar esses desafios foi aliar o ensino da disciplina Comércio Internacional às demandas práticas do projeto realizado na Unidade de Inteligência Comercial, con- 
forme apresentado na seção a seguir. Entende-se que o Projeto de Pesquisa foi uma oportunidade para que os estudantes desenvolvessem sua capacidade investigativa, analítica e lógica, além de aprimorarem competências requeridas de um profissional competitivo, como capacidade de trabalho em grupo, cumprimento das tarefas e prazos, solução de problemas e superação de situações de insucesso. Embora o projeto não conte com a participação de todos os alunos que cursam a disciplina Comércio Internacional, visto o número limitado de vagas para pesquisador-estudante, entende-se que a experiência foi positiva para os que participaram, sendo considerada válida sua exposição para a comunidade acadêmica.

\section{A DISCIPLINA COMÉRCIO INTERNACIO- NAL: UM DIFÍCIL PROCESSO DE ENSINO- APRENDIZAGEM}

Em geral, as disciplinas do núcleo de Economia são percebidas pelos alunos de Relações Internacionais como matérias que apresentam maior grau de dificuldade, sejam elas as introdutórias ou aquelas que exigem maior conexão com conceitos de Relações Internacionais e Política. Talvez isso ocorra porque muitos deles pensam que, ao escolher um curso essencialmente da área de Humanidades, ficarão longe dos números ou gráficos. Mostrar que, ao contrário, os números são instrumentais e absolutamente úteis e necessários para o aprendizado de um futuro analista de Relações Internacionais é um desafio para o professor que ministra a disciplina Comércio Internacional.

Outro desafio refere-se ao fato de que o aluno normalmente cursa a disciplina Co- mércio Internacional pensando que ele será um curso técnico de Comércio Exterior e que, por isso, aprenderá conteúdo que engloba legislação e rotina aduaneira, Sistema integrado de comércio exterior (SISCOMEX) e Códigos do comércio exterior, os International Commercial Terms (Incoterms), entre outros itens. Dessa forma, para evitar falsas expectativas, o professor precisa explicar, desde o início do curso, que o conteúdo da disciplina Comércio Internacional não é igual a de Comércio Exterior. O comércio exterior per se das nações está incluído no conteúdo da matéria Comércio Internacional, mas a parte técnico-operacional de Comércio Exterior é discutida em outra disciplina e tem caráter operacional.

A despeito das variações que existem no ementário das instituições, normalmente, o núcleo-duro da disciplina Comércio Internacional inclui: Teorias de Comércio Internacional; liberalismo e protecionismo no comércio internacional e sua evolução histórica; instrumentos de política comercial; o Sistema Multilateral de Comércio Internacional: o Acordo Geral sobre Tarifas e Comércio (GATT) e a Organização Mundial do Comércio (OMC); principais temas e obstáculos às negociações multilaterais; blocos econômicos regionais e acordos preferenciais de comércio internacional; análise do desempenho do comércio exterior brasileiro e de alguns dos principais players internacionais.

A introdução do curso aborda o debate sobre as trocas comerciais que, desde 0 século XV, realizaram-se cada vez mais no âmbito internacional à medida que o comércio se tornou de longa distância, quando as grandes navegações europeias moldaram as relações mercantis e o capitalismo selou seu modo de produção e funciona- 
mento. Em seguida, parte-se para o item destinado às Teorias do Comércio Internacional: a Teoria das Vantagens Absolutas, a Teoria das Vantagens Comparativas e as Teorias Neoclássicas de Comércio. Neste ponto, é necessário ficar claro para os estudantes que as primeiras são o germe analítico do liberalismo econômico e que dali se derivaram diversas outras teorias que tentaram explicar a realidade do comércio internacional e influenciar a formulação de políticas comerciais dos Estados em diversos períodos, sobretudo na Europa. Como esta parte introdutória tem um fundo histórico, está relacionada à ideologia hegemônica de cada momento e é essencialmente teórica, aos olhos dos alunos ela parece distante da realidade do século XXI.

Além disso, quando esses modelos são ensinados, é inevitável que se utilize cálculos dos custos de oportunidades para saber se há ou não comércio entre dois ou mais países, ainda que os modelos sejam simplificados. A fim de cativar a atenção e o interesse do discente, a todo o momento cabe ao professor remeter a exemplos mais recentes, ressaltando sempre o contexto em que cada pensador formulou tais abordagens, as críticas que elas sofreram posteriormente e as modificações implementadas ou as premissas refutadas. Nestas ocasiões, os alunos resistentes a fazer cálculos, mesmo que simples, podem compreender meIhor a ideia central de cada teoria a partir da visualização de gráficos. A despeito de serem ilustrativos, os exercícios posteriores, que se recomenda que sejam feitos em grupo, são fundamentais para fixação do conteúdo.

Antes da discussão mais geral sobre o Sistema de Comércio Internacional do GATT/OMC, a conceituação de política co- mercial de um país e seus objetivos, a apresentação dos instrumentos de política comercial, tanto das barreiras para evitar as importações, quanto dos diversos tipos de subsídios para estimular as exportações, podem ser contemplados no debate em sala. Dado o grande número de barreiras ao comércio internacional, inclusive o de barreiras técnicas - muitas delas tão recentes e "camufladas" nas ações dos governos -, os exemplos reais são excelentes ferramentas para ilustração, uma vez que para o aluno é difícil memorizar tantos nomes ou mesmo identificar o que é uma barreira técnica ao comércio. Trazer para o debate em sala de aula exemplos dos instrumentos que o Brasil ou os Estados Unidos utilizam e que são mais explorados pela mídia para explicar como cada um desses países pode inibir a concorrência de bens e serviços estrangeiros ou estimular um ou outro setor exportador, constituem uma forma eficiente para mostrar para os estudantes que decorar tudo não é a melhor estratégia de aprendizado.

É importante que este conteúdo, que não deixa de ter um caráter mais técnico, o que é geralmente exigido em concursos de diversas carreiras da área pública, seja assimilado antes da discussão sobre o Sistema de Comércio Internacional, que agrega desde os objetivos do surgimento do GATT, em 1947, até os entraves mais recentes enfrentados pela OMC para a conclusão da Rodada Doha, a última das rodadas de negociações multilaterais, embora não concluída após quase dezesseis anos de negociações. Isso porque o aluno precisará pensar as barreiras comerciais e em suas implicações nas negociações em cada uma das rodadas, de modo que tenha uma visão crítica do discurso do livre comércio e das políticas pro- 
tecionistas colocadas em prática pelos principais players do comércio internacional. Portanto, para analisar o GATT e a OMC do ponto de vista da Economia Política Internacional, o aluno terá dificuldades para compreender por que algumas barreiras são tão difíceis de serem eliminadas ou acordos de serem fechados, caso não tenha entendido bem cada uma das barreiras previamente, ou seja, sem saber como o protecionismo, de fato, é colocado em prática pelos governos, apesar da retórica de muitos deles em favor do livre comércio.

As configurações mais recentes de poder no Sistema Internacional e como elas se refletem na OMC podem ser abordadas a partir de um debate aberto pelos alunos. Dada a dificuldade de acompanharem o noticiário internacional, tanto porque geralmente não têm o hábito da leitura quanto porque, de fato, as mudanças são muito rápidas e concomitantes a vários outros acontecimentos, o professor precisa, à medida do possível, chamar a atenção para as atualizações. Este é o caso, por exemplo, dos acordos preferenciais de comércio que se proliferam bilateral e minilateralmente e que coexistem com os acordos regionais de comércio mais antigos. A rapidez com que eles são negociados e promulgados, ou até mesmo desfeitos, e suas inovações constituem temas cada vez mais instigantes em comércio internacional na atualidade e, por isso, crescentemente debatidos e pesquisados. Decerto, mapas que ilustram como eles se distribuem e gráficos que mostram como se comportam e se espalham no mundo auxiliam esta etapa do aprendizado.

Por fim, apesar do interesse do alunado sobre o desempenho do comércio exterior da China e dos Estados Unidos, por exemplo, certamente ele deve ter domínio e crí- tica acerca do desempenho do comércio exterior brasileiro ao longo das décadas, considerando as mudanças em política comercial e as condições de competitividade internacional de bens, serviços e setores com melhor e pior performance, uma vez que eles estão diretamente relacionados às escolhas de política comercial e de política industrial dos governos eleitos e à conjuntura internacional.

Diante dos desafios que se impõem aos docentes para tornar o ensino de Comércio Internacional inteligível e interessante aos alunos, o estudo de caso apresentado a seguir expõe uma oportunidade de aproximar o conteúdo teórico discutido em sala de aula a atividades práticas de pesquisa em inteligência comercial, permitindo aos estudantes correlacionar conceitos, desenvolver capacidade analítica e outras habilidades valorizadas no mercado de trabalho. Quanto aos docentes, este projeto permite que conceitos abstratos possam ser ilustrados com exemplos práticos e que seja demonstrado que o trabalho na área de Comércio Internacional é mais amplo que Comércio Exterior e pode ser utilizado para apoiar a formulação de políticas comerciais que tenham impacto na economia, seja do Estado ou do país.

\section{UMA EXPERIÊNCIA PRÁTICA EM RELA- ÇÕES INTERNACIONAIS: A UNIDADE DE INTELIGÊNCIA COMERCIAL}

Em 2014, na esteira do bom desempenho da economia fluminense e da grande projeção nacional e internacional da cidade do Rio de Janeiro, a SSRI buscou realizar parcerias com instituições de ensino superior com o objetivo de apoiar seu trabalho de interlocução entre o Governo do Estado 
e atores internacionais, intensificando e solidificando a relação entre eles. À época, os mega-eventos internacionais, como a Conferência das Nações Unidas sobre Desenvolvimento Sustentável (Rio+20), a Copa das Confederações, que aconteceu em junho de 2013, a Copa do Mundo de 2014, os preparativos para as Olimpíadas Rio 2016 e a forte ligação da economia fluminense à indústria do petróleo, que trouxe grandes empresas para o Estado, contribuíram positivamente para a inserção internacional da economia fluminense.

Diante de tantas responsabilidades, um dos maiores desafios da Assessoria de Comércio e Investimentos da SSRI ${ }^{1}$ era conciliar o atendimento da forte demanda proveniente dos seus interlocutores externos e o seu trabalho de assessoramento da inserção do Estado do Rio de Janeiro na cena internacional, buscando parceiros públicos e privados que possibilitassem o Estado a concretizar o seu programa de desenvolvimento ${ }^{2}$.

Desde que foi criada, em 2007, as principais atribuições da SSRI são: a atração de investimentos externos diretos para o Estado e a promoção do comércio exterior e de atividades relacionadas à construção da imagem do Rio no exterior; o trabalho de inteligência comercial; a organização de outreachs (missões em que o Estado procura se aproximar das empresas, cuja presença no Rio é considerada interessante para determinados setores) e de roadshows (es-

${ }^{1}$ A SSRI está dividida em cinco áreas: quatro Assessorias temáticas (Cooperação Internacional, Comércio e Investimentos, Financiamentos Externos, Relações Institucionais) e a Assessoria Especial.

2 Disponível na página da SSRI: <http://www.ri.gov.br/w eb/internacional/exibeconteudo?article-id $=2480949>$. Acesso em 13/02/2017. pécies de rodadas de negócios em que se convida as empresas para apresentar o estado).

A Assessoria de Comércio e Investimentos ainda coordena o Plano Nacional da Cultura Exportadora (PNCE) no Estado. Este plano, lançado em 2012 pelo Ministério do Desenvolvimento, Indústria e Comércio Exterior (MDIC) - atual Ministério da Indústria, Comércio e Serviços -, desde 2016, está ligado ao Plano Nacional de Exportações, que consiste, segundo o novo governo, em uma estratégia pragmática de integração às redes internacionais de acordos e aos fluxos de comércio mundiais ${ }^{3}$. Na prática, ambos buscam oferecer aos Estados brasileiros ações ligadas à cultura exportadora por meio da mobilização e capacitação de gestores públicos, empresários de pequeno e médio porte, além de profissionais de comércio exterior. Sua finalidade é estimular a realização de diagnósticos setoriais, programar as ações de apoio às exportações dos Estados, visando a diversificação dos destinos, das origens e da pauta brasileira de exportações.

Em virtude da estrutura organizacional enxuta, do volume de trabalho e da natureza técnico-investigativa da atividade de pesquisa proposta, ligada ao Comércio Internacional, a SSRI, por intermédio da FAPERJ, abriu editais públicos de fomento de pesquisa técnica, no final de 2014, para a candidatura de instituições de ensino superior, de modo que elas ficassem responsá-

\footnotetext{
3 Entre as prioridades para 2016 estão o acordo de livre comércio com a União Europeia, ampliação da facilitação de comércio com os EUA e acordos com os países da Bacia do Pacífico. Disponível na página oficial do Ministério da Indústria, Comércio e Serviços: <http:// www.mdic.gov.br/galeria-de-videos?videoid=bLk9op qu4gw>. Acesso em 13/02/2017.
} 
veis pelo trabalho de pesquisa em inteligência comercial no biênio seguinte, com possibilidade de renovação da parceria. A contrapartida do trabalho de pesquisa realizada pelas instituições vencedoras seria um aporte financeiro para a montagem de um Núcleo de Inteligência, que além de comércio, englobou as áreas de investimentos e cooperação para o desenvolvimento em outros dois centros de ensino superior.

A partir do anúncio dos vencedores, no princípio de 2015, teve início o trabalho estruturado e sistemático com os parceiros da SSRI. Para tanto, foi necessário que a Coordenação do Curso de Relações Internacionais do Unilasalle-RJ fizesse um processo seletivo para preenchimento das vagas de pesquisador-estudante. Em princípio seis alunos foram selecionados para compor a Unidade de Inteligência Comercial, supervisionados por quatro professores. À medida que a equipe concluía suas tarefas, novas seleções de estudantes foram realizadas, totalizando 18 alunos envolvidos no projeto até o presente momento.

O Unilasalle-RJ ficou designado para trabalhar na área de Inteligência Comercial. Seu intuito era apontar novas maneiras de fazer negócios, a partir do fornecimento de informações contínuas e análises comparativas e setoriais sobre o desempenho do comércio exterior fluminense, apontando perspectivas em novos mercados. Em outras palavras, o objetivo específico da pesquisa era a transformação de dados brutos relativos ao comércio exterior do Estado do Rio de Janeiro em informações estratégicas, que gerassem conhecimento para subsidiar as decisões dos gestores públicos de diversas secretarias.

A cooperação com a SSRI, pouco tempo depois de firmada por acordo, rendeu para a instituição acadêmica a montagem de uma sala aparelhada com computadores com acesso anual à base de dados de comércio exterior - o Funcexdata - da Fundação Centro de Estudos do Comércio Exterior (Funcex). A partir daí, estava pronta para funcionar, em março de 2015, a Unidade de Inteligência Comercial, um espaço para o desenvolvimento da pesquisa e realização de reuniões pela equipe envolvida no projeto. Poucos meses depois, foram aprovadas duas bolsas de iniciação científica da FAPERJ para discentes do curso de Relações Internacionais, que compunham o grupo de pesquisadores.

Juntamente com os professores, os estudantes realizaram imediatamente curso de capacitação em base de dados de comércio ministrado por funcionário estatístico da Funcex e, em seguida, receberam treinamento dos assessores da própria SSRI sobre a utilização das bases de dados abertas de comércio disponíveis na internet: AliceWeb ${ }^{4}$ e Radar Comercial ${ }^{5}$. Alguns deles haviam participado, em 2014, de outro curso de treinamento oferecido por um técnico do MDIC, no âmbito do Programa Redeagentes, com conteúdo focado no tema exportação ${ }^{6}$. O curso e o material didático foram totalmente gratuitos e, como contrapartida, o MDIC demandou local de treinamento e apoio administrativo durante a realização das atividades. Mais uma vez, a oportunidade foi alcançada com intermediação da

\footnotetext{
${ }^{4} \mathrm{O}$ site do AliceWeb é: <http://aliceweb.mdic.gov.br/>. Acesso em 14/02/2017. A base é mantida pelo MDIC.

${ }^{5} \mathrm{O}$ site do RadarComercial, desenvolvido pela Secretaria de Comércio Exterior (Secex) do Brasil, é: <http://radar comercial.mdic.gov.br/o-que-e-o-radar $>$. Acesso em 10/02/2017.

${ }^{6}$ As informações sobre o Programa estão disponíveis em: <http://www.mdic.gov.br/comercio-exterior/pnce /1626-redeagentes>. Acesso em 13/02/2017.
} 
SSRI, que colocou a Coordenação do Curso de Relações Internacionais em contato com o responsável pelo Programa Redeagentes, em Brasília.

Desde que a parceria entrou em vigor, foi acordada a entrega de oito "produtos" entre as partes, seguindo um cronograma definido de trabalho. $O$ primeiro produto foi o Panorama Comercial do Estado do Rio de Janeiro, que envolvia análise mais abrangente das condições econômicas do Estado, levando-se em consideração as suas relações comerciais; análise dos parceiros comerciais; análise dos bens produzidos pelo Estado; análise das cidades produtoras e das Micro, Pequenas e Médias Empresas. O segundo produto era o Boletim de Comércio Exterior do Estado do Rio de Janeiro, que consistia na apresentação dos principais acontecimentos no âmbito comercial, tendo como foco os anos de 2014, 2015, 2016 e 2017. O terceiro produto era composto pelos Estudos Setoriais de Potenciais Mercados, considerando os mercados de Jóias e Bijuterias, Bebidas Destiladas, Moda Praia, Moda Íntima, Rochas Ornamentais, Biotecnologia, Design, Artesanato, Metalmecânico. Tais setores foram escolhidos pela SSRI em razão de estudos anteriores sobre seu potencial.

O quarto produto era o Observatório de tradings, cujo fim era o mapeamento das tradings e a análise do seu desempenho em termos comparativos entre os anos 2013, 2014, 2015 e 2016. O quinto produto versava sobre a participação em eventos para apresentação dos resultados, com o intuito de conferir visibilidade ao projeto. Embora os alunos tenham participado pouco dos eventos ocorridos na SSRI, as publicações, que compunham o sexto produto da pesquisa, renderam bons frutos. Além do Bole- tim de Comércio Exterior, a produção de artigos técnicos, elaborados a partir dos produtos supracitados, trouxe informações e dados inéditos e de interesse da comunidade de gestores do setor público e privado, de empresários do Rio de Janeiro e, ainda, de interessados em investir no Estado. O sétimo produto envolvia a organização de eventos de divulgação e discussão dos resultados e, por fim, o oitavo englobava a análise setorial das micro, pequenas e médias empresas do Estado do Rio de Janeiro, com o intuito de analisar os seus desafios e potencialidades.

No que tange à participação em eventos, a equipe do projeto participou da XI Semana de Relações Internacionais, em outubro de 2015, e da VI Semana de Prática e Pesquisa em Relações Internacionais, em maio de 2016, ambos no Unilasalle-RJ. Na primeira ocasião, os discentes puderam aprender com a exposição do Programa Exporta Fácil dos Correios ${ }^{7}$. Na última, o coordenador do Projeto apresentou os principais resultados, bem como um aluno bolsista expôs sua hipótese e conclusões descritas em artigo acadêmico sobre os efeitos do choque do petróleo para o Estado do Rio de Janeiro, considerando a grande dependência fluminense deste produto em sua pauta de exportação e a crise econômica que afetou o Estado mais recentemente.

Os discentes também participaram do lançamento do PNCE na Casa do Empresário no Rio de Janeiro, em 2016, com o objetivo de representar o Projeto e principalmente compreender as implicações dele para o Estado do Rio de Janeiro. Participaram, ademais, do 3 Seminário de Relações Inter-

\footnotetext{
7 Programa ExportaFácil dos Correios, disponível em: <http://www2.correios.com.br/exportafacil/interna.ht $\underline{\mathrm{ml}}>$. Acesso em 13/02/2017.
} 
nacionais da ABRI, em setembro de 2016, em Florianópolis, apresentando pôster relacionado à pesquisa. Com relação às publicações, em 2015 e 2016 foram divulgados os resultados da pesquisa na Revista Economia Rio, com artigos ilustrados. Atualmente, os discentes estão elaborando artigos científicos, visando à publicação em revistas acadêmicas e congressos.

Para cumprir o cronograma e desenvolver os produtos a serem entregues, entre os anos de 2015 e 2017 foram realizados encontros periódicos com membros da SSRI, a fim de delimitar os objetivos específicos de cada produto ou mesmo corrigi-los ou ainda adaptá-los às necessidades do órgão público, fosse alinhando-os às necessidades da Secretaria Estadual de Desenvolvimento Econômico ou das Subsecretarias da Casa Civil, da qual a SSRI faz parte. Também ocorreram reuniões quinzenais entre os docentes e discentes envolvidos no projeto, com a finalidade de organizar e desenvolver os relatórios de pesquisa, assim como readequar o calendário de entrega dos produtos, a divisão de tarefas e o modo de trabaIho de acordo com os pedidos da SSRI.

Nesse mesmo período, os discentes, sob supervisão dos professores, elaboraram Panoramas Comerciais do Estado do Rio de Janeiro dos anos 2014, 2015 e 2016, Boletins de Comércio Exterior com periodicidade mensal acerca do desempenho do comércio exterior do Estado em cada trimestre a partir de 2015, Estudos Setoriais de Potenciais Mercados para as Pequenas e Médias empresas do Rio de Janeiro, contemplando os setores Jóias e Bijuterias, Bebidas Destiladas, Moda Praia, Moda Íntima e Rochas Ornamentais.

Como mencionado neste artigo, o projeto de pesquisa tem como finalidade apoiar a formulação de políticas públicas do governo do Estado do Rio de Janeiro. Nesse sentido, todos os estudos desenvolvidos pela Unidade de Inteligência Comercial do Unilasalle-RJ são encaminhados para a equipe da SSRI que objetiva repassar o material para empresas dos setores investigados, bem como instituições públicas e privadas que trabalhem em prol da exportação e da atração de investimentos do Estado. A intenção da SSRI é possibilitar às empresas o acesso a informações técnicas que possam auxiliá-las na tomada de decisões relacionadas à exportação e ao investimento no estado.

De fato, a SSRI trabalha em parceria com uma gama de entidades para promover a competitividade das empresas públicas e privadas instaladas no Rio de Janeiro, como a Secretaria de Estado de Desenvolvimento Econômico, Energia, Indústria e Serviços (SEDEIS). Enquanto a Assessoria de Comércio e Investimentos atua direcionada ao internacional, com atividade relacionada à análise de atração de investimentos externos diretos para o Estado e a promoção do comércio exterior, a SEDEIS trabalha no âmbito doméstico, formulando a política estadual de desenvolvimento, incentivando as atividades da iniciativa privada, buscando promover a competitividade das empresas públicas e privadas instaladas no estado (SEDEIS, 2016) ${ }^{8}$. Assim, a partir dos estudos prospectivos e analíticos gerados na Unidade de Inteligência Comercial do UnilasalleRJ em parceria com a SSRI, a SEDEIS pode apoiar o desenvolvimento do comércio exterior das empresas fluminenses.

Para além da SEDEIS, a SSRI também tra-

\footnotetext{
8 Disponível em: <http://www.ri.gov.br/web/sedeis/>. Acesso em: 15 ago. 2016.
} 
balha em parceria com outros órgãos como a Federação das Indústrias do Estado do Rio de Janeiro (FIRJAN) e o Serviço Brasileiro de Apoio às Micro e Pequenas Empresas (SE$B R A E$ ), entidades que trabalham para promover a competitividade e o desenvolvimento das empresas fluminenses. Dessa forma, os documentos técnicos gerados pelo projeto também podem servir como ferramentas para tomadas de decisão para que estas instituições utilizem em seus trabalhos de assessoria com as empresas do Estado do Rio de Janeiro. O objetivo também é repassar as informações e análises para sindicatos setoriais e empresas do setor.

Até o presente momento os documentos gerados ao longo do projeto foram utilizados pela SSRI como fontes para apresentação e para reuniões com outras instituições públicas e privadas. A Assessoria de Comércio e Investimentos já mapeou os setores e empresas que serão beneficiados com as informações de inteligência comercial geradas no projeto e a lista é extensa, podendo trazer bons resultados para o comércio do Estado no curto e médio prazo. Consequentemente, além do projeto de pesquisa realizado no âmbito do Unilasalle-RJ capacitar os estudantes na realização de análises comerciais, pesquisas técnicas, elaboração de documentos oficiais e estudos analíticos e prospectivos para o Governo do Estado, sendo um projeto que não se limita à produção acadêmica, mas envolve também o âmbito prático que envolve as decisões comerciais.

Após apresentação do campo de ensino nas Relações Internacionais no Brasil, dos seus desafios e oportunidades e de como o Unilasalle-RJ vem buscando unir teoria e prática no ensino do Comércio Internacio- nal por meio de um projeto de pesquisa que tem como finalidade auxiliar a formulação de políticas públicas governamentais, a seção a seguir apresenta uma breve conclusão sobre o tema.

\section{CONCLUSÃO}

Nos últimos anos, estudos sobre o Ensino e a Pesquisa em Relações Internacionais no Brasil vêm destacando o desenvolvimento e a institucionalização da área acadêmica, a criação e a expansão de inúmeros cursos de graduação, pós-graduação e extensão, o histórico da produção científica e do debate intelectual, além dos desafios e perspectivas existentes no ensino e na inserção dos estudantes no mercado de trabalho (HERZ, 2002; MIYAMOTO, 2003; LESSA, 2005). A criação de um subcampo temático sobre Ensino e Pesquisa, é um sinal do esforço que vem sendo feito no país para estimular discussões e trocas de experiências, permitindo que o ensino seja aperfeiçoado.

Com efeito, ensinar para que os alunos alcancem formação sólida, ampla e crítica não é uma tarefa simples para educadores em qualquer nível. Ainda mais quando se trata de um curso de graduação relativamente recente no Brasil frente a uma gama enorme de novos cursos e de outros de forte tradição no país. Por isso, a todo o momento, o estudante e o bacharel em Relações Internacionais precisam buscar oportunidades que confirmem seu diferencial e seu nicho em um mundo que está em constante transformação e cujo mercado de trabalho se mostra cada vez mais exigente. Ao mesmo tempo, esse mesmo mercado demanda tarefas que não são estáticas ou triviais e tampouco pré-determinadas e rotineiras, como antigamente, mas estão em 
constante metamorfose e exigem ações rápidas, dinâmicas e eficientes de seus profissionais.

Neste âmbito, tanto ensinar quanto aprender são desafios cada vez maiores e que devem ser pensados e reformulados para evitar momentos monótonos em sala de aula e para superar a falta de interesse dos alunos por certos temas ou disciplinas. Assim, entende-se que é possível superar métodos ultrapassados e que estão muito longe da realidade dos alunos. Especialmente em razão do enorme fluxo de informações e das mudanças sociais e comportamentais, mais do que nunca, é preciso refletir e trocar experiências exitosas que podem ser difundidas e até mesmo aperfeiçoadas por outras instituições de ensino e em outros campos de estudo.

Pensando neste contexto, o Projeto de Pesquisa conjunta com a SSRI foi apresentado e foram discutidos sua operacionalização e resultados. Ademais, destacaram-se os principais desafios e oportunidades no ensino e na aprendizagem no Curso de Relações Internacionais, de forma geral, e na disciplina Comércio Internacional, em particular, a partir de uma experiência considerada exitosa. A despeito das repercussões positivas, este é um estudo de caso que demonstra que, acima de tudo, deve ser constante a procura pela renovação do ensino, tanto em resposta aos estudantes na rotina das aulas, quanto ao competitivo mercado de trabalho.

\section{REFERÊNCIAS}

ALICEWEB. Disponível em: <http://alicewe b.mdic.gov.br/>. Acesso em 14/02/2017. ALMEIDA, Paulo Roberto. As relações internacionais como oportunidade profissional:
Respostas a algumas das questões mais colocadas pelos jovens que se voltam para as carreiras de relações internacionais. Meridiano 47, v. 67, 2006, p. 5-10.

EXPORTAFÁCIL. Disponível em: < http://ww w2.correios.com.br/exportafacil/interna.ht $\underline{\mathrm{ml}}>$. Acesso em 13/02/2017.

HERZ, Mônica. O Crescimento da Área de Relações Internacionais no Brasil. Contexto Internacional, v. 24, n.1, 2002, p.7-40. LESSA, Antônio Carlos. Instituições, atores e dinâmicas do ensino e da pesquisa em Relações Internacionais no Brasil: o diálogo entre a história, a ciência política e os novos paradigmas de interpretação (dos anos 90 aos nossos dias). Revista Brasileira de Política Internacional, v.48, n.2, 2005, p.169-184. MINISTÉRIO DA INDÚSTRIA, COMÉRCIO E SERVIÇOS. Disponível em: <http://www.mdi c.gov.br/galeria-de-videos?videoid=b Lk9op qu4gw>. Acesso em 13/02/2017.

MIYAMOTO, Shiguenoli. O Ensino das Relações Internacionais no Brasil: problemas e perspectivas. Revista de Sociologia e Política, v.20, 2003, p. 103-114.

PROGRAMA REDEAGENTES. Disponível em: $<$ http://www.mdic.gov.br/comercio-exteri or/pnce/1626-redeagentes>. Acesso em 13/02/2017.

RADARCOMERCIAL. Disponível em: < http:// radarcomercial.mdic.gov.br/o-que-e-o-rad ar>. Acesso em 10/02/2017.

SECRETARIA DE ESTADO DE DESENVOLVIMENTO ECONÔMICO, ENERGIA, INDÚSTRIA E SERVIÇOS (SEDEIS). Disponível em: <http://www.ri.gov.br/web/sedeis/>. Acesso em: 15 ago. 2016.

SUBSECRETARIA DE RELAÇÕES INTERNACIONAIS DO ESTADO DO RIO DE JANEIRO. Disponível em: <http://www.rj.gov.br/web/ internacional/exibeconteudo?article-id=248 0949>. Acesso em 13/02/2017. 
VIGEVANI, Tullo; THOMÁZ, Laís Forti; LEITE Lucas Batista. As Relações Internacionais no Brasil: notas sobre o início de sua institucionalização. Inter-Relações, ano 14, n.40, 2014, p. 5-11. 